\title{
Effects of Information Communication Technology on Urban and Rural Service Sectors: An Empirical Analysis of Japanese Economic Geography
}

\author{
Hideyuki Tanaka, Takeshi Okamoto \\ The University of Tokyo, Graduate School of Interdisciplinary of Information \\ Studies, \\ 7-3-1, Hongo, Bunkyo-ku, Tokyo, Japan
}

\begin{abstract}
The present paper investigates the impacts of information communication technology (ICT) on economic geography by focusing on the Japanese service sectors. The authors empirically assess the effects of ICT on the urban and rural service sectors using Japanese economic data. There are two main findings. The first indicates that the service sectors in urban areas agglomerated from 2000 to 2006. The second is that the ICT environment might affect the location of the service sectors; an especially dense ICT service could accelerate agglomeration in urban areas. However, the effects of the ICT-related environment on the location of the service sectors are different in urban and rural areas. A dense ICT service environment might disperse service sectors in a rural area.
\end{abstract}

\section{Introduction}

The present paper investigates the impacts of information communication technology (ICT) on economic geography by focusing on the Japanese service sectors. ${ }^{1}$ Service sectors have become the main engine of the world economy, accounting for approximately $70 \%$ of aggregate production and employment in OECD countries (OECD 2005). In Japan, the service sector share of total employment has risen from

\footnotetext{
${ }^{1}$ Section 4 will show the types of service industries included in present analysis.
} 
$47 \%$ in 1970 to $67 \%$ in $2005^{2}$. The service sectors play a major role in the Japanese economy and affect the country's urban structure.

From a geographical viewpoint, service sectors were previously concentrated in urban areas because of the sectors' focus on the spatial distribution of the demand for their services (Tabuchi and Thisse 2006). One of the characteristics of service is direct or face-to-face interaction between provider and consumer, which is difficult to provide beyond a certain distance. The share of the service sector market in the thirteen largest Japanese cities ${ }^{3}$ was more than ten points larger than the remaining cities combined in $2006^{4}$.

ICT affects several aspects of the service sectors. The development of ICT has reduced communication and coordination costs across distances. Services can be provided from a distance using ICT, including e-commerce, digital music, and on-line support. A significant cost reduction could induce or accelerate sector agglomeration in urban areas based on the core-periphery argument (Krugman 1991). The productivity of the sectors has also been advanced by ICT. Historically, improvement of service sector productivity has been difficult. The labor intensiveness of the services provided has made productivity advancements more difficult than in the manufacturing sector, for which productivity improvements could be made through mechanization. This phenomenon, known as Baumol's cost disease, has been altered through ICT, which provides opportunities for the service sector innovation (Baumol 1961). Innovative sectors have been shown to prosper in large, diverse metropolitan areas (Henderson et al. 1995). Consequently, sector expansion and agglomeration in urban areas may be facilitated by ICT.

The research question explored in the present study is whether ICT accelerates or deters service sector agglomeration. The impact of ICT on the urban structure has been disputed for more than a decade, as is described in Section 2. However, previous quantitative empirical studies have not assessed the impacts on service sector agglomeration. In addition, few empirical studies of ICT and urban agglomeration have been based on quantitative data collected in Japan. The authors intend to contribute to economic geography by using recent Japanese empirical data to evaluate the role of ICT in the service sectors. The remainder of the paper is organized as follows. Section two surveys related literature, section three describes the methodology used in the empirical analyses. Section four summarizes the Japanese statistical data and the empirical analyses. Section five assesses the agglomeration of the service sectors and section six investigates impacts of ICT on service sector agglomeration. The authors discuss the results in section seven and conclude the research in section eight.

\footnotetext{
${ }^{2}$ The figures are based on the 2005 National Census of Japan.

${ }^{3}$ The thirteen cities are consistent with the data used in the empirical analyses. The cities are the ordinance-designated cities as of 2000: Sapporo, Sendai, Chiba, Tokyo-special wards, Yokohama, Kawasaki, Nagoya, Kyoto, Osaka, Hiroshima, Kitakyushu, and Fukuoka.

${ }^{4}$ The service sectors account for $84 \%$ of the employment in the 13 largest cities and $72 \%$ in the remaining urbanized areas, based on the 2006 Establishment and Enterprise Census.
} 


\section{Related Literature}

The role of ICT in determining the location of economic activity has been evaluated previously. One of the main arguments addresses whether ICT is a substitute for or a complement to face-to-face interaction. If the former effect is indicated, economic activity is liberated from geographic limitations. If ICT complements personal interaction, services should remain concentrated in urban areas (Gaspar and Glaeser 1998).

Empirical research has identified two effects of ICT on the need for face-to-face communication. The first type (Type I) investigates the effects of ICT adoption on urban agglomeration. Using data for U.S. ICT workers, Kolko (2002) contends that ICT raises the speed of spatial dispersion and lowers the level of industry concentration by controlling the distribution of educated workers. Ioannides et al. (2008) present international data supporting the assertion that increases in the number of telephone lines per capita encourage spatial dispersion of population. Contrary to these results, which suggest a substitution effect, Biteux-Orain and Guillain (2004) reveal that a complement effect exists in addition to the substitute effect in face-to-face interaction based on French data.

The second effect (Type II) deals with the influence of the urban environment on ICT adoption. Zook (2002) argued that the regional distribution of venture capital investment played a central role in determining the location of new Internet startups. Pons-Novell and Viladecans-Marsal (2006) conducted a survey in the province of Barcelona and showed that off-line commercial distribution in cities affected the Internet availability. Forman et al. (2003, 2005a, b) introduced a new outlook on the face-to-face argument based on the General Purpose Technology (GPT) theory (Bresnahan and Trajtenberg 1995). They identified two purposes for adopting the Internet in business; one is participation and the other is enhancement. Examples of the former are e-mail and web-browsing, i.e. the basic purposes, and those of the latter are e-commerce and security, i.e. the complex purposes. Their empirical studies show that the urban environment affects ICT adoption when the latter purpose is sought. ICT users require support by skilled labor or technical support such as system engineers, software consultancy, and IT system integrators. Urban settings make it possible to supply the dense technical supports for firms by means of face-to-face interactions. Furthermore, firms in urban areas could effectively adopt ICT as GPT and change their business model or organization.

Recent empirical works shed light on ICT-related service sectors (hereafter, ICT service sector) demonstrating that technical or professional support by the ICT service sectors plays a key role in the effective implementation of IT systems for business use. The ICT service sectors are concentrated in urban areas. Isaksen (2004) explains the reasons for the clustering of the Norwegian software sector in the Oslo area based on the need for face-to-face support. Aslesen and Isaksen (2007) reveal that urban firms use consultancy services more frequently than those located outside of urban areas. Arora and Forman (2007) show that the magnitude of local ICT services significantly influences the decision to out-source software programming and design. 
Prior studies deal with the relationship between ICT adoption and urban structure or between the ICT-related urban environments and ICT adoption (Table 2.1). The present authors aim to verify the relationship between the ICT-related urban environments and urban structure (Type III) and focus on local ICT service sectors as an ICT-related urban environment. Furthermore, the goal of the present study is to determine whether the urban ICT environment affects urban structure through latent technology adoption.

Table 2.1

Prior studies and the authors study

\begin{tabular}{|l|r|r|}
\hline ICT-related urban environments (a) & ICT adoption (b) & Urban structure (c) \\
\hline & $\begin{array}{r}\text { Type I }(\mathrm{b}<=>\mathrm{c}) \\
\text { Kolko(2002), Ioannides et al.(2008), } \\
\text { Biteux-Orain and Guillain (2004) }\end{array}$ \\
\hline Type II (a<=>b) \\
$\begin{array}{r}\text { Zook (2002), Pons-Novell and Viladecans-Marsal (2006), Forman et al. } \\
(2003,2005 \mathrm{a}, \mathrm{b}), \text { Arora and Forman (2007), Aslesen and Isaksen(2007) }\end{array}$
\end{tabular}

\section{Methodology}

The basic economic model of the present research is based on the summaries of three theories regarding dynamic externalities in urban environments provided in Glaeser et al. (1992). The first theory is the Marshall-Arrow-Romer (MAR) externality. The first externality concerns knowledge spillovers between firms in an industry (localization). The concentration of an industry in a city helps firms to share knowledge spillovers and enhances the growth of that industry and city. The theory predicts that a local monopoly is better for growth than local competition because the flow of ideas to other firms is restricted by local monopoly. The second theory is the Porter (1990) externality. The theory states that knowledge spillovers in specialized, geographically concentrated industries stimulate growth. In contrast, local competition fosters the pursuit and rapid adoption of innovation (competition). The third theory is Jacobs' (1969) study of diverse urban economies, in which the most important knowledge transfers come from outside the core industry. The externality is derived from a buildup of knowledge or ideas associated with historical diversity. Similar to Porter (1990), Jacobs (1969) favors local competition. Glaeser et al.(1992) extended three theories into the following model.

$A_{t} f\left(l_{t}\right)$ is the production function of a firm in a certain industry, where $A_{t}$ represents the overall level of technology at time $t$ measured nominally, and $l_{t}$ is the labor input at time $t$. Each firm in this industry takes technology, prices, and wages, $w_{t}$, as given and maximizes equation (3-1). 


$$
A_{t} f\left(l_{t}\right)-w_{t} l_{t} \quad(3-1)
$$

Labor input is set so as to equate the marginal product of labor to its wage, as in equation $(3-2)$.

$$
A_{t} f^{\prime}\left(l_{t}\right)=w_{t}(3-2)
$$

(3-2) can be rewritten in terms of growth as equation (3-3).

$$
\log \left(A_{t+1} / A_{t}\right)=\log \left(w_{t+1} / w_{t}\right)-\log \left(f^{\prime}\left(l_{t+1}\right) / f^{\prime}\left(l_{t}\right)\right)(3-3)
$$

$A_{t}$ contains national and local technology (3-4).

$$
\begin{aligned}
& A_{t}=A_{\text {local }} A_{\text {national }}(3-4) \\
& \log \left(A_{t+1} / A_{t}\right)=\log \left(A_{\text {local },+1} / A_{\text {local }, t}\right)+\log \left(A_{\text {national },+1} / A_{\text {nationall }, t}\right)
\end{aligned}
$$

The local technology is assumed to grow at a rate exogenous to the firm but is dependent on various technological externalities present in this industry in the city, as in equation (3-6)

$\log \left(A_{\text {local },++1} / A_{\text {local }, t}\right)=g($ specialization, competition, diversity, initial conditions $)+e_{t+1} \quad(3-6)$

If we set $\mathrm{f}(l)=l^{1-\alpha}, \mathrm{o}<a<1$, we can obtain equation (3-7) $\alpha \log \left(l_{t+1} / l_{t}\right)=-\log \left(w_{t+1} / w_{t}\right)+\log \left(A_{\text {national },+1} / A_{\text {nationall }, t}\right)+g($ specialization, competition, diversity, initial conditions $)+e_{t+1}(3-7)$

Equation (3-7) allows us to associate the growth of employment in a particular industry in a city with measures of technological externalities given by the above theories. In the following section, we will empirically assess the effect of the ICT-related environment as one of the initial conditions based on equation (3-7).

\section{Data}

The data set is composed of four Japanese government statistics: the Establishment and Enterprise Census conducted by the Ministry of Internal Affairs and Communications (MIC); the Population Census conducted by MIC; the Survey of Selected Service Industries conducted by the Ministry of Economy, Trade and Industry (METI); and the Basic Survey on Wage Structure conducted by the Ministry of Health, Labor and Welfare (MHLW).

The data set contains information on employment, payroll, number of establishments, and education by two-digit sector. The authors obtained wages by dividing payroll by employment. The limitations of the data structure require that we use data for the 13 ordinance-designated cities and 47 prefectures. Data from prefectures that contain a major city/cities exclude the data for the city/cities. There are 60 statistical divisions in the data. The service sectors are classified according to the Japan Standard Industrial Classification, and include sectors $\mathrm{H}$ (Information and Communications) to Q (Services, N.E.C), excluding I (Transport). The one-digit sector I is omitted because payrolls data could not be obtained. Furthermore, the following two-digit sectors are excluded because of changes in the classifications in 2004: 37, 40, 41, 68, $69,78,94$. Although, there could be a maximum 2,640 area-sectors, we finalized 2,578 area-sectors as basic observations because certain area-sectors have no employment. In the following sections, we exclude outliers beyond mean plus standard deviation (SD) x 4 or below mean minus SDx4 for some variables. 
Following Glaeser et al. (1992) and Kolko (2002), the authors use a natural logarithm of the sector-area employment growth rate from year 2000 to year 2006 as a proxy for agglomeration (or dispersion). The dependent variable is $\ln E \mathrm{mpG}$.

$\ln E m p G_{i x}: \ln E m p_{i x}{ }^{2006}-\ln E m p_{i x}{ }^{2000}$ : employment growth from 2000 to 2006

Independent variables are defined as follows. The first three variables correspond, respectively, to specialization, competition, and diversity in equation (3-7).

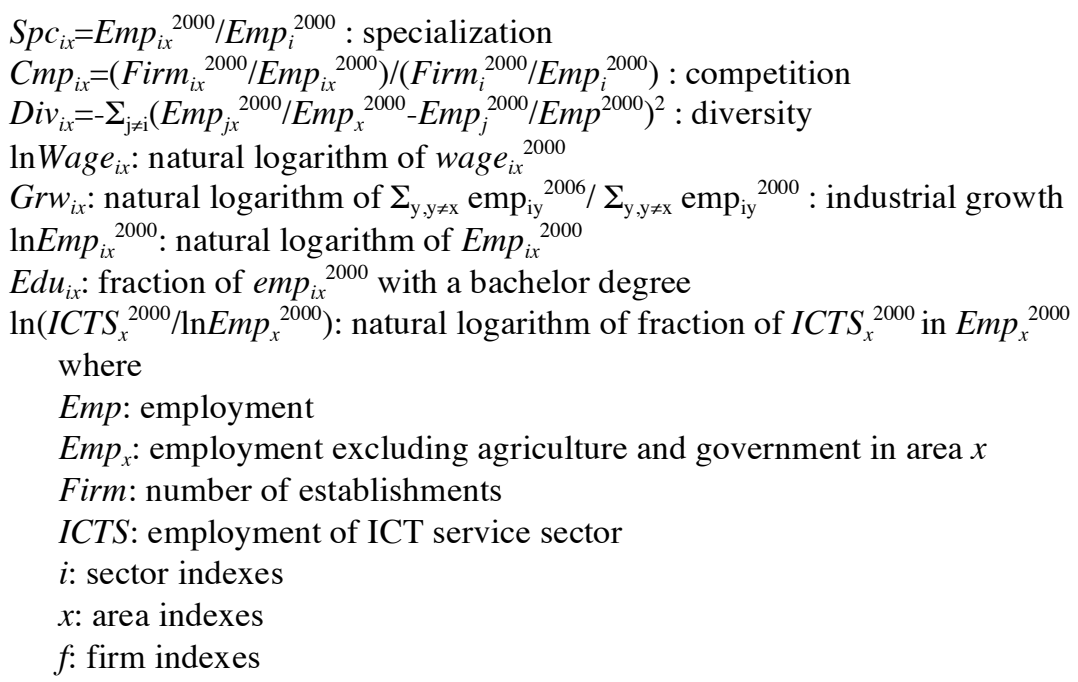

\section{Analysis 1: Service Sector Agglomeration}

In the current section, the authors assess service sector agglomeration. The evaluation utilizes sample data that consist of all service sectors, including the ICT service sector. Summaries of the statistics and the correlation of variables are shown in Table 5.1 and Table 5.2, respectively. 


\section{Table 5.1}

\section{Variable means and standard deviations}

\begin{tabular}{lrrrr}
\hline \multicolumn{1}{c}{ Variable } & \multicolumn{1}{c}{ Mean } & \multicolumn{1}{c}{ SD } & \multicolumn{1}{c}{ Max } & \multicolumn{1}{c}{ Min } \\
\hline $\ln$ EmpG $_{\text {ix }}$ & .035 & .307 & 1.370 & -1.247 \\
Specialization $_{i x}$ & .014 & .013 & .130 & .000 \\
Competition $_{i x}$ & 1.209 & .427 & 3.600 & .280 \\
Diversity $_{i x}$ & -.003 & .001 & -.001 & -.007 \\
lnWage $_{i x}$ & 15.274 & .145 & 15.741 & 14.951 \\
${\text { Industry } \text { growth }_{i x}}$ & .040 & .227 & .764 & -.283 \\
lnEmp $_{\text {ix }}$ 2000 & 8.483 & 1.544 & 12.439 & 3.425 \\
lnEdu $_{i x}$ & -1.623 & .807 & -.278 & -7.637 \\
\hline
\end{tabular}

Observations: 2525

Table 5.2

Correlation of variables

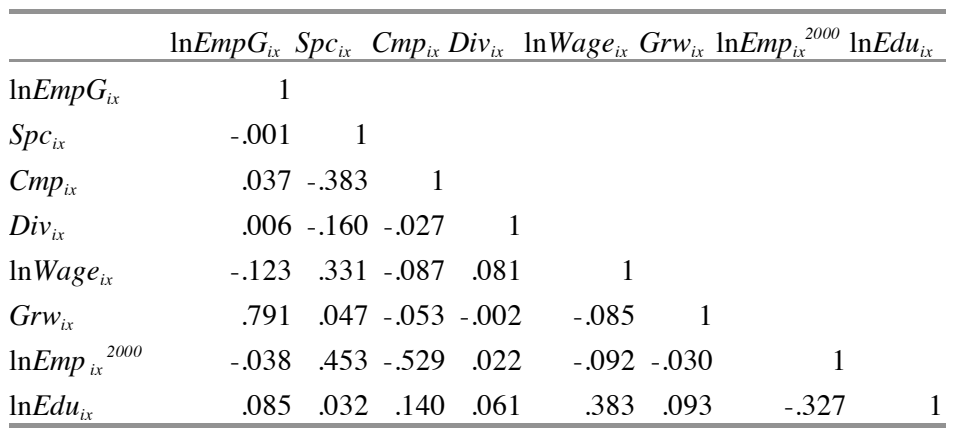

$\ln E m p^{2000}$ is used as an explanatory variable. If the coefficient of the variable is significantly positive, this indicates that the higher the employment in service sector $i$ in area $x$, the more employment grows. This relationship leads to agglomeration.

The results are shown in Table 5.3. The coefficients for $\ln E m p_{i x}{ }^{2000}$ are significantly positive in column (1) and (2). However, the coefficient in column (3) is not significant. These results support the notion that the service sectors are agglomerating in Japan, but only in urban areas and not throughout the country.

In the next section, we investigate the effect of the ICT environment on service sector agglomeration. 
Table 5.3

City-Industry employment growth between 2000 and 2006

\begin{tabular}{|c|c|c|c|}
\hline \multirow[b]{2}{*}{ Variable } & \multicolumn{3}{|c|}{$\begin{array}{l}\text { Dependent variable: } \\
\ln E m p G_{i x}\end{array}$} \\
\hline & $(1)$ & $(2)$ & (3) \\
\hline \multirow[t]{2}{*}{ Specialization $_{i x}$} & -.073 & -1.042 & .564 \\
\hline & $(.358)$ & $(.586)$ & $(.711)$ \\
\hline \multirow[t]{2}{*}{ Competition $_{i x}$} & .065 & .064 & .066 \\
\hline & $(.010)$ & $(.027)$ & $(.014)$ \\
\hline \multirow[t]{2}{*}{ Diversity $_{i x}$} & 3.200 & -5.359 & 8.063 \\
\hline & $(3.065)$ & (7.935) & $(5.174)$ \\
\hline \multirow[t]{2}{*}{$\ln W a g e_{i x}$} & -.119 & .052 & -.161 \\
\hline & $(.031)$ & $(.084)$ & $(.039)$ \\
\hline \multirow[t]{2}{*}{ 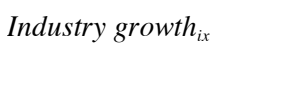 } & 1.067 & .958 & 1.096 \\
\hline & $(.017)$ & $(.036)$ & $(.021)$ \\
\hline \multirow[t]{2}{*}{$\ln E m p_{i x}{ }^{2000}$} & .008 & .025 & .001 \\
\hline & $(.003)$ & $(.007)$ & $(.004)$ \\
\hline \multirow[t]{2}{*}{$\ln E d u_{i x}$} & .013 & -.003 & .016 \\
\hline & $(.005)$ & $(.013)$ & $(.006)$ \\
\hline \multirow[t]{2}{*}{ Constant } & 1.700 & -1.102 & 2.408 \\
\hline & $(.479)$ & $(1.304)$ & (.616) \\
\hline Adjusted $\mathrm{R}^{2}$ & .635 & .563 & .668 \\
\hline Observations & 2525 & 543 & 1555 \\
\hline
\end{tabular}

Column (1): Over all of Japan; Column (2): 13 cities; Column (3): 36 prefectures that do not have any major cities.

\section{Analysis 2: Impacts of the ICT Service Sector}

To determine the effects of ICT on service sector agglomeration in urban areas, this section investigates the relationship between the ICT-related environment and the urban structural changes, focusing on service sectors.

The variable $\ln \left(I C T S_{x}{ }^{2000} / \ln E m p_{x}{ }^{2000}\right)$ is added in this analysis. This variable is a proxy for the ICT-related environment. Firms in areas with high ICTS proportion could easily access ICT support services. The firms might use ICT effectively with co-invention, or innovation, creating a business model or organization that is more suitable for ICT. Consequently, those firms may grow more than those in the area with a low-ICTS proportion.

Tables 6.1 and 6.2 show summaries of statistics and the correlation of variables by date in major cities, respectively. 
Table 6.1

Summary of statistics (13 cities)

\begin{tabular}{|c|c|c|c|c|}
\hline Variable & Mean & SD & Max & Min \\
\hline $\ln E m p G_{i x}$ & .005 & .283 & 1.036 & -.875 \\
\hline Specialization $_{i x}$ & .029 & .050 & .491 & .001 \\
\hline Competition $_{i x}$ & .904 & .325 & 3.257 & .280 \\
\hline Diversity $_{i x}$ & -.003 & .001 & -.000 & -.007 \\
\hline $\ln$ Wage $_{i x}$ & 15.364 & .122 & 15.741 & 15.192 \\
\hline Industry growth $_{i x}$ & .035 & .227 & .759 & .333 \\
\hline $\ln E m p_{i x}{ }^{2000}$ & 8.842 & 1.563 & 12.913 & 3.802 \\
\hline $\ln E d u_{i x}$ & -1.363 & .689 & -.311 & -3.978 \\
\hline $\ln \left(\right.$ ICTS $_{x}{ }^{2000} /$ Emp $\left._{x}{ }^{2000}\right)$ & -4.288 & .626 & -2.81 & -5.227 \\
\hline
\end{tabular}

Observations: 551

Table 6.2

Correlation of variables $(13$ cities $)$

\begin{tabular}{|c|c|c|c|c|c|c|c|c|}
\hline & \multicolumn{2}{|c|}{$\ln E m p G_{i x} S p c_{i x}$} & $C m p_{i x}$ & $\operatorname{Div}_{i x}$ & \multicolumn{2}{|c|}{$\operatorname{lnWage}_{i x} G r w_{i x}$} & \multicolumn{2}{|r|}{$\begin{array}{c}\ln \left({ }^{\prime C T S} S_{x}{ }^{00}\right. \\
\left.u_{i x} \quad / \operatorname{Emp}_{x}{ }^{00}\right)\end{array}$} \\
\hline $\ln E m p G_{i x}$ & 1 & & & & & & & \\
\hline$S p c_{i x}$ & -.013 & 1 & & & & & & \\
\hline $\mathrm{Cmp}_{i x}$ & -.038 & -.238 & 1 & & & & & \\
\hline$D i v_{i x}$ & -.019 & -.594 & .116 & 1 & 1 & & & \\
\hline $\ln _{\text {Wage }}{ }_{i x}$ & -.063 & .478 & -.139 & -.401 & 1 & & & \\
\hline$G r w_{i x}$ & .737 & -.055 & -.094 & .010 & -.828 & 1 & 1 & \\
\hline $\ln E m p_{i x} 2000$ & .031 & .400 & -.318 & -.329 & .067 & -.084 & 1 & \\
\hline $\begin{array}{l}\ln E d u_{i x} \\
\ln \left(I C T S_{x}{ }^{2000}\right.\end{array}$ & -.009 & .135 & .122 & -.016 & .272 & .022 & -.270 & 1 \\
\hline$\left(E m p_{x}{ }^{2000}\right)$ & .052 & .347 & -.143 & -.623 & .362 & -.018 & .171 & 93 \\
\hline
\end{tabular}

Observations: 551

The results are provided in Table 6.3. The data in columns (1) and (2) consist of all service sectors, excluding the ICT service sector in major cities. The estimate of the variable, $\ln E m p_{i x}{ }^{2000}$, in column (1) shows that service sectors have also agglomerated although the ICT service sector is excluded from the sample. The ICT service impact can be seen in the estimation of the variable, $\ln \left(\operatorname{ICTS}_{x}{ }^{2000} / \operatorname{Emp}_{x}{ }^{2000}\right)$, which is significantly positive. This result supports the contention that the ICT-related environment affects service sector agglomeration in urban areas. The more ICT service industries located in an area, the more accelerated is the agglomeration of the other service sectors.

In addition, the authors assessed the impact of ICT services on service sectors in rural areas. Column (3) shows those results. The coefficient of $\ln \left(\right.$ ICTS $_{x}{ }^{2000} /$ Emp $_{x}$ 
${ }^{2000}$ ) is negative. Although the significance level is between $5 \%$ and $10 \%$, the ICT environment might negatively affect the location of the service sectors in rural areas. The more ICT service sectors located in an area, the more probable the other service sectors might disperse rather than agglomerate.

Table 6.3

City-Industry employment growth between 2000 and 2006

\begin{tabular}{|c|c|c|c|}
\hline \multirow[b]{2}{*}{ Variable } & \multicolumn{3}{|c|}{ Dependent variable: $\ln E m p G_{i x}$} \\
\hline & (1) & $(2)$ & $(3)$ \\
\hline \multirow[t]{2}{*}{ Specialization $_{i x}$} & -.005 & .063 & .029 \\
\hline & $(.226)$ & $(.227)$ & $(.770)$ \\
\hline \multirow[t]{2}{*}{ Competition $_{i x}$} & .061 & .069 & .082 \\
\hline & $(.0270)$ & $(.027)$ & $(.014)$ \\
\hline \multirow[t]{2}{*}{ Diversity $_{i x}$} & 1.118 & 13.380 & 9.649 \\
\hline & $(7.215)$ & $(8.537)$ & $(5.159)$ \\
\hline \multirow[t]{2}{*}{$\ln$ Wage $_{i x}$} & .0120 & -.019 & -.170 \\
\hline & $(.080)$ & $(.081)$ & $(.039)$ \\
\hline \multirow[t]{2}{*}{ Industry growth $_{i x}$} & .941 & .943 & 1.106 \\
\hline & $(.036)$ & $(.036)$ & $(.020)$ \\
\hline \multirow[t]{2}{*}{$\ln E m p_{i x}^{2000}$} & .021 & .021 & .005 \\
\hline & $(.006)$ & $(.006)$ & $(.004)$ \\
\hline \multirow[t]{2}{*}{$\ln E d u_{i x}$} & -.001 & -.004 & .022 \\
\hline & $(.013)$ & $(.013)$ & $(.006)$ \\
\hline \multirow[t]{2}{*}{$\ln \left(\operatorname{ICTS}_{x}{ }^{2000} / \operatorname{Emp}_{x}{ }^{2000}\right)$} & - & .045 & -.018 \\
\hline & - & $(.017)$ & $(.010)$ \\
\hline \multirow[t]{2}{*}{ Constant } & -.455 & .233 & 2.400 \\
\hline & $(1.241)$ & $(1.262)$ & $(.618)$ \\
\hline Adjusted $\mathrm{R}^{2}$ & .551 & .556 & .679 \\
\hline Observations & 551 & 551 & 1515 \\
\hline
\end{tabular}

Column (1) and (2): 13 cities; Column (3): 36 prefectures that do not have any major cities.

\section{Discussion}

The results of analysis 1 suggest that the service sectors in urban areas might agglomerate. However, the authors could not verify the spatial distribution direction of the rural service sectors.

The results of analysis 2 suggest two different effects of the ICT environment on service sector location. In urban areas, a dense ICT service environment might accelerate the agglomeration of other service sectors. In contrast, a dense service environment in a rural area might accelerate dispersion of other service sectors, although the significant level is not particularly high. 
The combination of the two analyses resulted in the authors' contention that the ICT environment or ICT itself accelerates a structural change in the location of the service sectors; from rural to urban. Furthermore, we should identify the ICT effect on economic geography. Figure 7.1 summarizes the above assertion.

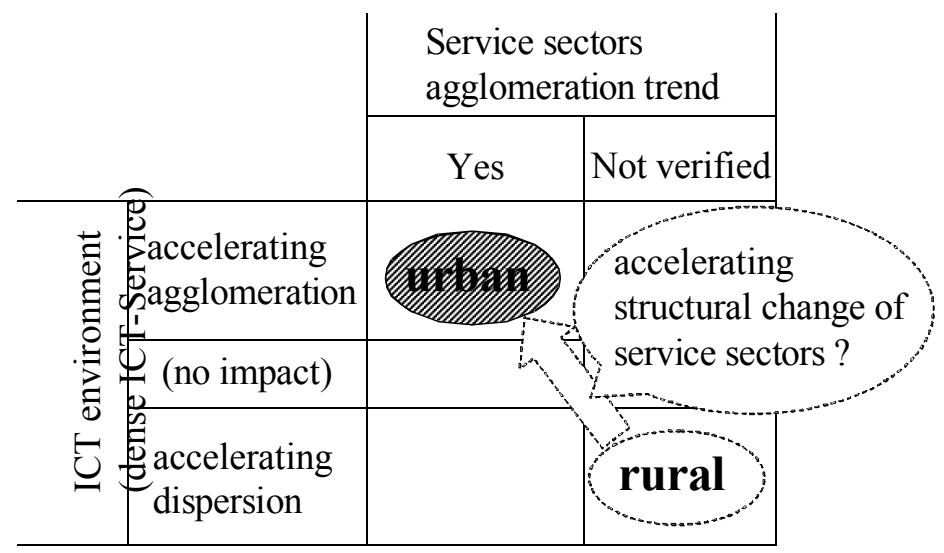

Fig. 7.1

Effects of ICT on urban and rural service sectors

\section{Conclusions}

The current research empirically assesses the effects of ICT on urban and rural service sectors using Japanese economic data. There are two main findings. The first conclusion is that service sectors in urban areas agglomerated from 2000 to 2006. The second is that the ICT environment might affect the location of the service sectors. In particular, an especially dense ICT service could accelerate agglomeration in urban areas. Furthermore, the effects of the ICT-related environment on the location of the service sectors might be different in urban and rural areas. A denser ICT service environment might disperse service sectors in a rural area.

The following three viewpoints were identified as the geographic impacts in the ICT research area. The first is the empirical assessment of the relationship between the ICT environment and urban structure. As shown in Table 2.1, prior literature evaluated the relationship between ICT adoption and the urban structure or between the ICT environment and ICT adoption. The present paper introduces a new perspective to this research area. The second contribution is the empirical assessment of the ICT effects on the agglomeration of service sectors. Prior ICT geographical analyses did not directly investigate the sectors' agglomeration. The third contribution is the analysis of the Japanese ICT environment and economic geography. Previously, few empirical studies dealt with the relationship between ICT and the Japanese economic geography. 
The present paper has three limitations. Firstly, the authors' analyses are based on two points in the time series, 2000-2006, due to lack of statistics. A future study based on longer time series would be needed to assess the present conclusion. Secondly, the present paper could verify the effects of ICT in rural areas by statistically but weakly significant results. The direction of rural services location will be discussed in future studies. Thirdly, the present paper focuses on the Japanese service sectors. One of the characteristics of the Japanese economic geography is the dispersion of the manufacturing sector in urban areas (Mano and Otsuka 2000) and future research should address the effects of ICT on the urban and rural manufacturing sectors. An evaluation of the combined service and manufacturing research will depict the structural changes in the urban and rural economies of Japan.

Acknowledgments The research was supported by a Grant-in-Aid for Scientific Research on Priority Areas, "New IT Infrastructure for the Information-explosion Era", funded by the Ministry of Education, Culture, Sports, Science and Technology. The support is gratefully acknowledged.

The authors thank two anonymous reviewers for their helpful comments.

\section{References}

Arora, A. \& Forman, C. (2007). Proximity and information technology outsourcing: How local are IT services markets? Journal of Management Information Systems, 24(2), 73-102.

Aslesen, H. W. \& Isaksen A. (2007). Knowledge intensive business services and urban industrial development. Service Industrial Journal, 27(3), 321-338.

Baumol, W. J. (1961:1977), Economic theory and operations analysis, Englewood Cliffs, N.J. : Prentice-Hal.

Biteux-Orain, C. \& Guillain R. (2004). Changes in the intrametropolitan location of producer services in Ile-de-France (1978-1997): Do information technologies promote a more dispersed spatial pattern? Urban Geography, 25(6), 550-578.

Bresnahan, T. F. \& Trajtenberg, M. (1995). General purpose technologies 'Engines of Growth'? Journal of Econometrics, 65, 83-108.

Forman, C., Goldfarb, A., Greenstein, S. (2003). The geographic dispersion of commercial Internet use. In Cranor, S. F. \& Wildman, S.S.(Eds.), Rethinking rights and regulations: Institutional responses to new communications technologies (pp.113-145). Cambridge, Mass: MIT Press.

Forman, C., Goldfarb, A. Greenstein, S. (2005a). How did location affect adoption of the commercial Internet? Global village vs. urban leadership. Journal of Urban Economics,58, 389-420.

Forman, C., Goldfarb, A. and Greenstein, S.(2005b). Geographic location and the diffusion of Internet technology. Electronic Commerce Research and Applications, 4, 1-13.

Gaspar, J. \& Glaeser, E.L (1998). Information technology and the future of cities. Journal of urban economics, 43, 136-156.

Glaeser, E. L. , Kallal, H.D., Scheinkman, J.A., Shleifer, A. (1992). Growth in Cities. The Journal of Political Economy, 100(6), Centennial Issue. 1126-1152.

Henderson, V., Kuncoro, A., Turner, M. (1995). Industrial development in cities. Journal of Political Economy, 103(5), 1067-1090.

Ioannides, Y. M., Overman, H.G., Rossi-Hansberg, E., Schmidheiny, K. (2008). The effect of information and communication technologies on urban structure. Economic Policy, April, 201-242.

Isaksen, A. (2004). Knowledge-based clusters and urban location: The clustering of software consultancy in Oslo. Urban Studies, 41(5), 1157-1174.

Jacobs, J. (1969), The economy of cities, New York: Vintage. 
Krugman, P. (1991). Increasing returns and economic geography. Journal of Political Economy, 99(3), 483-499.

Kolko, J. (2002). Silicon mountains, silicon molehills: Geographic concentration and convergence of Internet industries in the US. Information Economics and Policy, 14, 211-232.

Mano, Y. \& Otsuka, K. (2000). Agglomeration economies and geographical concentration of industries: A case study of manufacturing sectors. Journal of the Japanese and International Economies, 14, 189-203.

OECD (2005), Enhancing the performance of the service sector, Paris: OECD.

Pons-Novell, J. \& Viladecans-Marsal, E. (2006). Cities and the Internet: The end of distance? Journal of Urban Technology, 13(1), 109-132.

Porter, M. E. (1990), The competitive advantage of the nations, New York: Free Press.

Tabuchi, T. \& Thisse, J. (2006). Regional specialization, urban hierarchy, and commuting costs. International Economic Review, 47(4), 1295-1317.

Zook, M. A. (2002). Grounded capital: Venture financing and the geography of the Internet industry, 1994-2000. Journal of Economic Geography, 2(2), 151-177. 